\title{
Design and development challenges for an E2E DRM content business integration platform
}

\author{
Antonio Hidalgo , José Albors , Vicente Lopez \\ Dept. Business Administration, Universidad Politécnica de Madrid, c/José Gutiérrez Abascal 2, 28006 Madrid, Spain \\ Dep. Business Administration, Universidad Politécnica de Valencia, c/Camino de Vera s/n, 46022 Valencia, Spain
}

\section{A R T I C L E I N F O}

Keywords:

Digital rights

Platform

$\mathrm{B} 2 \mathrm{~B}$

\begin{abstract}
A B S T R A C T
Current studies on Digital Rights Management (DRM) have focused on controlling access to and copies of contents, centered exclusively on the end of the value chain (end users). This focus has been oriented towards security and encryption as a means of solving the issue of illegal copying by purchasers. In this paper, we propose End-to-End Digital Rights Management (E2E DRM) that involves the protection of the content throughout the entire value chain. This concept is given form in the new technologies for representing intellectual property (IP) which, in a secure and unequivocal manner, identify the content at each point in the value chain: from the author to the end user, the content is identifiable in any of the transactions and statuses through which it passes. The key concept which E2E DRM must provide is not only the governability of access and copying, but also that of all the processes associated with the content business. We establish an E2E DRM model and architecture, and propose the R\&D management of its design and implementation that makes it possible to protect content from content creator to purchaser. Finally, the paper also analyzes their impact from a global perspective.
\end{abstract}

\section{Introduction}

The expansion of the mobile telephone market and the Internet has led to major worldwide growth in the last decade. The global turnover of mobile telephony services in 2006 amounted to 470 billion Euros, the number of mobile phone customers went from 2 billion in 2005 to 2.6 billion in 2006, and it is anticipated that by the end of 2008 more than half of the world's population will have access to a mobile phone (ENTER, 2007). Meanwhile, the Internet saw $10 \%$ growth worldwide in 2007 , with 1.1 billion users, and it is anticipated that by 2010 this number will have increased to 1.6 billion (WSIS, 2007). At the same time, the content market (television, cinema, video rentals, music, games, news, etc.) has seen worldwide growth, facilitated by the implementation of digital technology. The per capita consumption of mobile content and applications in the United States was 17\%, compared to 64\% in Europe, where 3 out of 5 young mobile users downloaded some kind of content in 2006. The content which has sold most is music and audio (37\%), including polyphonic and monophonic ringtones; graphic content (34\%), including logos, wallpaper and SMS images; and Java games (12\%) (OECD, 2007). Forecasts suggest that in 2009 Internet sales of digital content in the music sector will make up $16 \%$ of total global music sales (10.7 billion dollars) and that major growth will be seen in digital video services over the period 2007-2010 (IDC, 2007).

The creation of independent, non-professional, individual content is increasing by the day and is becoming increasingly decentralised. The most important new challenges facing the digital audiovisual market include three main objectives: the production of high-quality digital audiovisual content, the improvement of distribution media and the requirements of the intellectual property(IP) rights covering this content. Current examples of initiatives in digital distribution include movies and digital video, new interactive formats, computerised distribution via Digital Rights Management (DRM), TDT and the experiences with high definition television and DVD. Similar challenges have been faced with printed content (Worlock, 2000) and open-source development, as is the case of Science and Creative Commons (Välimäki \& Pitkanen, 2001; Lichtenthaler, 2007).

In order to carry out an analysis of the technologies involved in the definition, construction and operation of platforms which take into account the concept of E2E DRM, it is necessary to identify the elements which make up the multimedia content value chain, the links between them and the information exchanged by them (Gauvin \& Delgado, 2006). The multimedia content value chain is formed by the group of users who act on the digital content in one way or another, thereby defining their role in the process, using for this purpose different devices, communication protocols between devices and data delivery protocols (Koenen, Lacy, Mackay, \& Mitchell, 2004). From a functional point of view, the implemen- 


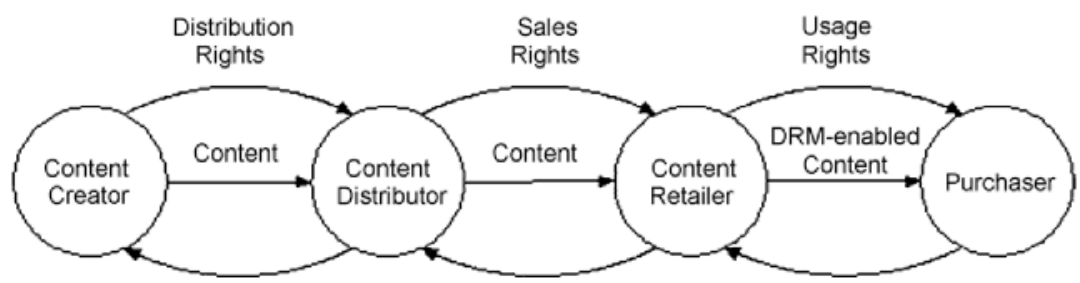

Fig. 1. Multimedia content value chain.

tation of a value chain involves a series of roles being fulfilled by its members: creation, production and provision of content, provision of services and consumption (see Fig. 1).

However, within this context, particular attention must be paid to aspects relating to the protection of intellectual property as a consequence of the fact that the digitalisation of text, audio and audiovisual content, and its communication by Internet, has irreversibly transformed the parameters of its application. On a regulatory level, the World Copyright Treaty (WCT) recognised the major impact of the development and convergence of Information and Communication Technologies (ICT) on the creation and use of literary and artistic works (WIPO, 1996). In 1998, the WCT was implemented in the United States by means of the Digital Millennium Copyright Act (DMCA), whilst in Europe it was not until 2001 that the European Council approved Directive 2001/29/EC, relating to the harmonisation of certain aspects of copyright in the information society. The design of the E2E DRM platform should therefore help to offer increased potential for facilitating the transfer of intellectual property (Välimäki \& Oksanen, 2006) and reduce the shortcomings that had previously limited its use.

Due to the exploratory nature of this research and the interest in identifying the activities and influences affecting the progress of innovation, a qualitative focus (case study) was adopted in the methodological approach chosen for this study. This study enabled us to collect data and create a theoretical model which could not be satisfactorily derived from existing theory. This approach makes it possible to explain the relevance of a variety of observations through in-depth and detailed insights, with consideration given to qualitative information and subjectivity resulting from the peculiarities of individual cases and the difficulties of general analyses (Eisenhardt, 1989; Pettgrew, 1990; Yin, 1994). The case study in this paper enables a detailed analysis of specific focal points within the model in question, such as their design and organisational structure, as a means of understanding how innovation has achieved specific objectives.

The aim of this paper is to propose an E2E DRM platform which can integrate all of the legitimate role-players and cover the content protection on the overall content distribution value-chains. We start with a review of recent trends in DRM technologies, and discuss the limitations and problems associated with the protection of content rights. We then propose an E2E DRM model, which includes its architecture, and propose R\&D management for its design and implementation, making it possible to protect content from its creation to its purchase. Finally, we discuss how this model can be used to successfully support the managerial implications in different scenarios, analysing their impact from a global perspective.

\section{State-of-the-art of DRM technologies}

The need for the exchange of information requires technologies and standards (McAllister, 2002) which cover the following aspects entailed by its use: content representation, identification and authentication; content licensing; content cataloguing, marketing, storage and distribution; user identification, authentication and certification; domains, tools and devices (software and hardware). New technologies have had a huge impact in the copyright field, as although they have enabled the emergence of new creation methods and media, as well as new ways of using the intellectual works, they also hinder copyright protection, as they make the monitoring of its use very complex (De Miguel, 2000).

DRM is a technology designed to protect and securely deliver content. In their early stages, DRM technologies were generally encryption based, and the security of the system was dependent on the secrecy of encryption keys. Previous studies on this topic have focused on security and encryption as a means of solving the issue of unauthorized copying, that is to say, locking content and limiting its distribution to purchasers (Sibert, 1995; Mulligan, Han, \& Burstein, 2003). An early example of a DRM system was the Content Scrambling System (CSS), used by the DVD Forum on DVD films since 1996. CSS used a simple encryption algorithm, and required device manufacturers to sign licensing agreements which restricted the inclusion of certain features, such as digital outputs that could be used to extract high-quality digital copies of the film, in their players (see Fig. 2). The only consumer hardware capable of decoding DVD films was thus controlled, albeit indirectly, by the DVD Forum, restricting the use of DVD media in other systems, until the release of DeCSS in 1999, which allowed a CSS-encrypted DVD to play properly on a computer using Linux (Eschenfelder, 2005). The CSS used by the DVD Forum is an example of a poor R\&D management strategy. We need look no further than CSS encryption for DVDs as an example of what happens when R\&D is left in device makers' hands.

Initially, digital content distribution models were organized on the basis that the principals trade content by means of a contract which relies on an agreement. The DRM systems were considered as access and copy control (ACC) systems, leaving to one side the representation of all the stages that the digital content goes through in the value chain, and focused exclusively on the relationship between the service provider and the end user (Cohen, 2003; Lee et al., 2003). The analysis of the ACC technologies revealed the limitations of the DRM model that they represented, as they were not strictly speaking DRM systems, but systems to restrict the use of content (Digital Restrictions Management). In all cases, the disadvantages of this model arose from the unidirectional and limited nature of the flow of information, which did not allow the creation of new business models by the distributor (Foroughi, Albin, \& Gillard, 2002; Hanaoka et al., 2004).

The limitations for the end user included the impossibility of identifying the rights over content, the exclusive control of the service provider, and the perception that the distributor is being paid for content without it being clear how the payment will be distributed among the different members of the value chain. The limitations for the content or services providers were centered around the fact that as the business was based on secrecy, they were forced to keep the system closed; in other words, based on proprietary standards which prevented interoperability with other distributors and meant that the user was forced to continue acquiring the audiovisual material from the same distributor (Von Lohmann, 2002). 


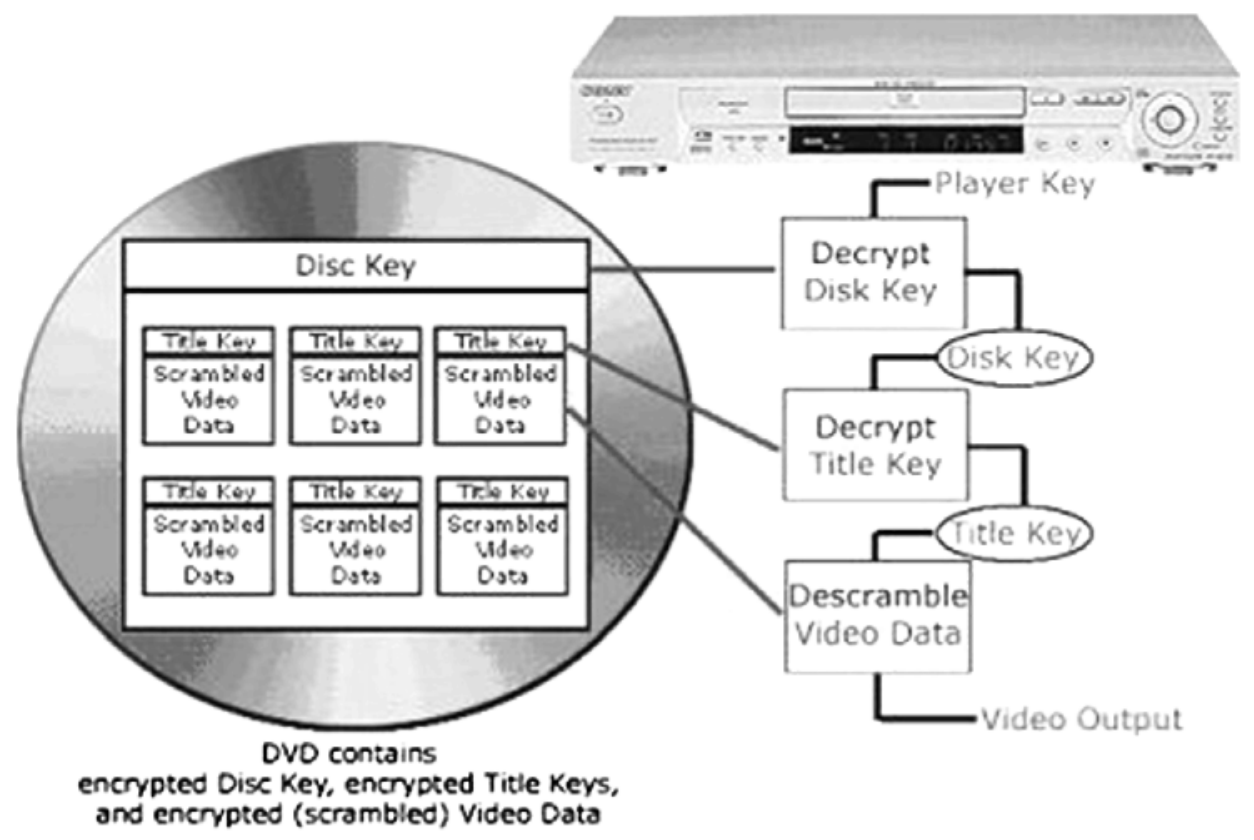

Fig. 2. Content Scrambling System (CSS).

Another content distribution model is also available through a Copyright Clearance Center (CCC) which has the role of managing copyrights entrusted with content by rights holders and to continually monitor content distribution in order to find illegal content use (see Fig. 3). However, current content distribution models have certain problems and limitations relating to content rights protection. Firstly, although a contract is entered into by the principals to transfer content rights, it cannot provide an objective and transparent enforcement of protection, monitoring and tracking all forms of content rights use, because the content will be maintained according to the principals' confidentiality agreement. Secondly, it cannot provide clarity and transparency for rights management. It is impossible to control and manage content which is distributed beyond the scope of the principals concerned. Finally, when breach of contract occurs it is difficult to forcefully control content distribution and to verify the facts in order to establish the breach of contract (Cohen, 2003; Jeong, Yoon, \& Ryou, 2005).

One critical aspect relates to the possibility of defining standards initiatives in DRM (Torres, Rodriguez, Llorente, \& Delgado, 2005). This issue has always been inherently problematic due to a combination of the complexity of DRM and the speed with which the digital media market is developing. Whereas a single, standardised worldwide technical solution for DRM is probably not advisable from a security point of view, a common standardised framework (such as the one being developed in MPEG-21 under the name of Intellectual Property Management and Protection, IPMP) would facilitate interoperability between terminals, servers and diverse
DRM solutions. This diversity of DRM solutions is also necessary in order to efficiently adapt to the variety of content types, business models and applications: it is quite obvious that there cannot be a one-size-fits-all single DRM solution (Gasser \& Palfrey, 2007).

\section{Design of the end-to-end DRM platform}

\subsection{E2E DRM model}

Following the analysis of these problems, the conclusion is that a rights management system based on the maintenance of secrecy is extremely inefficient, making it advisable to change the paradigm to models in which this secrecy does not exist (Hare, 1999; Koepsell, 2000 ), or in which its relative importance in the exchange of audiovisual material is drastically reduced. If we consider content protection and relationships among principals who do not trust each other, content should be protected not only among purchasers but also among other principals (Van Tassel, 2006; Huang, 2007). The solution is therefore to change the conception of a business based on mistrust of the user (access to content is restricted because unauthorised use will otherwise be made of it), and replace it with another based on trust (all the information is visible and everyone benefits from the system).

We propose an E2E DRM model which can cover content protection throughout the content distribution value chain, with the following characteristics:

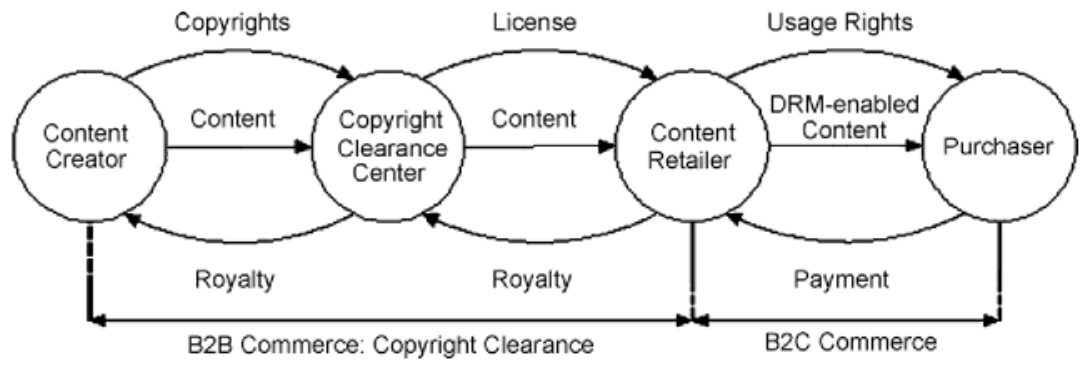


- A transparent model, in which there is integrated management of the rights which produce the intellectual property incorporated into the final content in each of the intermediate processes, from conception to distribution (Camp, 2003).

- An interrelationship model, in which the digital content moves freely between the different members of the value chain, without there being any individuals or entities which can unilaterally impose their conditions. The aim is to create an environment of trust in which there are no privileged users, and it is therefore necessary to design mechanisms for the inclusion of information relating to users which makes it possible to associate the intellectual property generated with completely identified individuals (Torres, Delgado, \& Llorente, 2006).

- A horizontal, open model in which anyone can carry out the distribution of their work without the need to go through preestablished or controlled channels. It is therefore necessary for the model to allow any user who distributes a work to express the rights exercised over the work by means of the appropriate rights expression language (REL).

- Incorporating a system for licensing the use of content which is flexible enough to cover the whole range of situations for possible uses of a licensed material.

All of the above leads us towards a model in which there is a clearly established separation between the container and the content. In the former case, the digital file where the work is encoded represents the box in which the audiovisual material is transferred during a transaction and should not impose limitations on the use of the material (the object of the transaction is the content, not the file). In the latter case, the content is the element which is inside the box, on which the system is focused. The model is therefore based on the interrelationship of all the users by means of the movement of content and its possible use as the basis for future works, an aim to which the container should not be a hindrance.

The proposed E2E DRM model includes the distribution of both the content encryption key and the content itself. Fig. 4 shows an E2E DRM model where the principals (creators, distributors and retailers) can transfer to the next principals (distributors, retailers and purchasers) their content and license containing the key to content distributed separately. It is important to highlight the roles of the clearing house, to authenticate the principal's request for a license, determine the principal's rights, issue a license and monitor the use of the issued license. In order to protect the content delivered to the next principal it is necessary to encrypt the content, which is locked with a key and bundled with additional information by a principal.This operation results in a DRM-enabled package content file which can be controlled under a license, and the principals may only use and redistribute this package within the scope of the rights specified in the license, which is issued by the previous principal. The use of rights of DRM-enabled content is required to be executed under the license.

In the proposed model, the most important elements and technologies for the creation of the environment of trust are as follows:

1. Representation of content: It is necessary to define a structure of elements representing all of the information generated, which can be found among the MPEG 21 Digital Item, DMP Content Information and Open Mobile Alliance (OMA) standards.

2. Representation of licences: Based on Rights Expression Languages (REL), the aim of which is the management of the licences and rights and restrictions on content. These include the Open Digital Rights Language (ODRL) and MPEG 21 REL standards.

3. Representation of tools for the protection and control of access to content, through the MPEG 21 IPMP or DMP standards. The already accepted component RDD (Rights Data Dictionary) defines a consistent vocabulary to describe users' rights.

4. Representation of tools and devices in use, linked to the transformations undergone by a particular content and the digital file representing it throughout their life cycle. It should be remembered that the content must be protected by means of cryptographic techniques and that in order to decode them a certain calculus power and the capacity to run a decryption program is necessary.

5. Representation of metadata, which consist of the incorporation of text describing the attributes of the documents, providing them with meaning, context and organisation. They may be descriptive (identifying the information resources to enable the search for and recovery of a particular category of image documents), structural (facilitating the navigation and presentation of electronic resources) and administrative (facilitating the short- and long-term management and processing of digital collections, including technical data on quality control and rights management). These include the Dublin Core and TV-Anytime standards.

6 . Representation of users to ensure the complete specification of information on intellectual property and rights over this intellectual property. The most appropriate standards include OpenID and Liberty Alliance.

7. Representation of the relationships between rights, actions and roles, which involves detailing the flow of intellectual property activities which lead to the creation of a particular work, as well as the flow of activities on the digital file. These include the Ontology Web Language (OWL) standard.

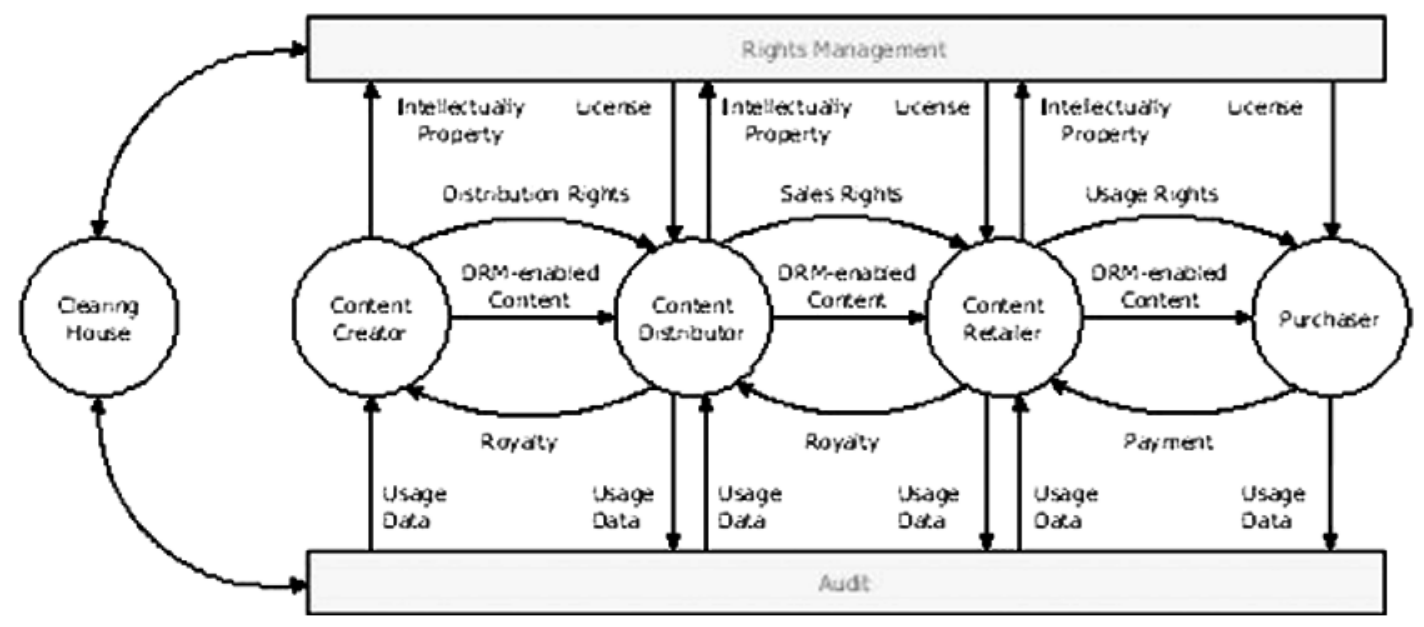




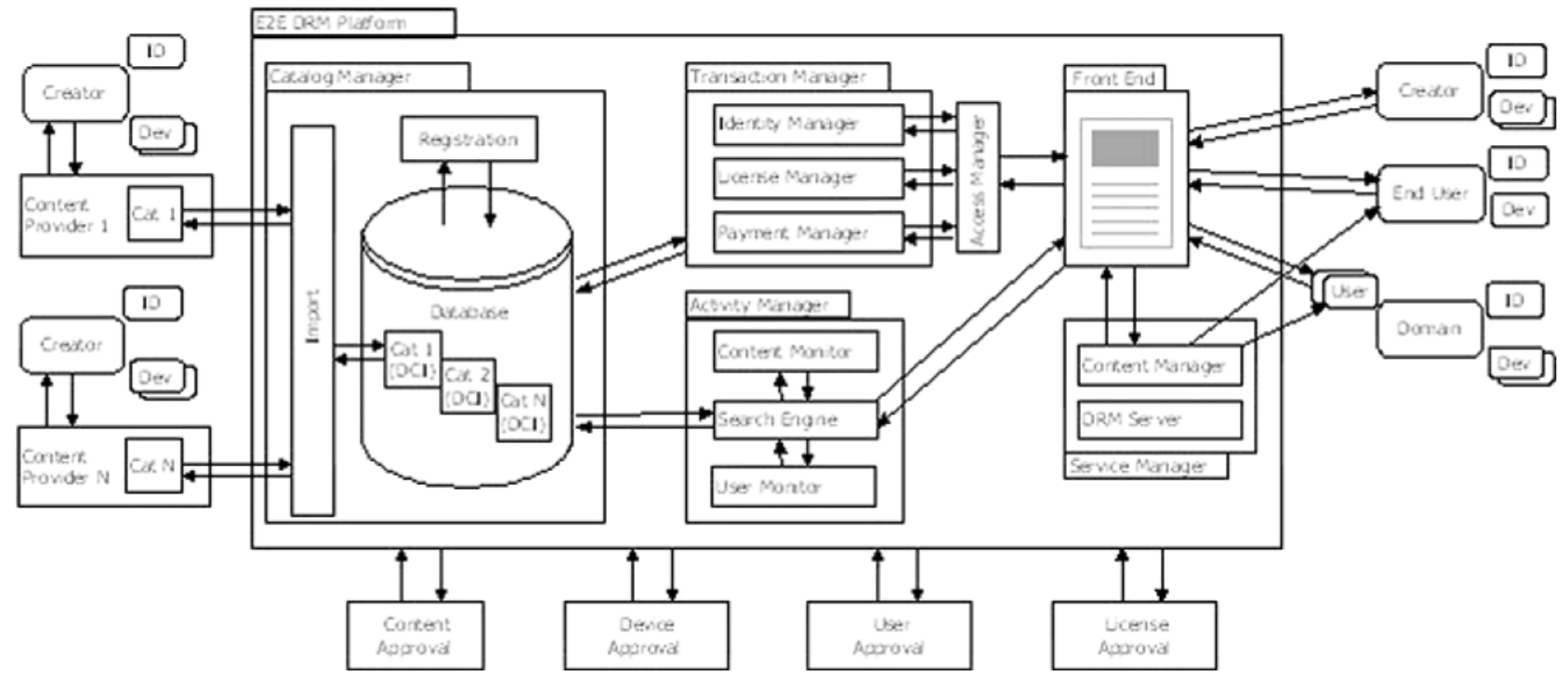

Fig. 5. Overall E2E DRM architecture.

\subsection{E2E DRM architecture}

The basic architecture of the E2E DRM platform is defined from two different, but mutually dependent, points of view: on the one hand, the interoperability and integrated management of intellectual property throughout the value chain in the content creation process and, on the other, the data requirements generated by these approaches. The starting hypothesis is to establish an exhaustive description of a particular work through the establishment of a digital object and to determine the type of information which must be included in this description. The result is a structure grouped into modules, each one of which is defined according to the nature of the services offered by the rest of the system, and which range from the management of internal resources, such as for example the database, to the final service provided to the user, such as for example the delivery of content, the invoicing for the services contracted or the downloading of encryption and decryption tools.

This logical structure is shown in Fig. 5, in which the following modules are proposed: front-end (FE), access manager (AM), activity manager (ATM), catalogue manager (CM), transaction manager (TM), service manager (SM) and user devices (Dev). In this paper, we expand the role and function of each component and establish the relationships between the components of an E2E DRM system in order to accommodate the overall content distribution value chains.

The front-end (FE) module allows the user to access the platform. Its design involves the development of on-line assistants to help the user to complete some of the more complex operations and offers technical knowledge not usually possessed by the user. These assistants cover the set-up of licences, helping the user in the choice and set-up of the content licensing methods in a registration process; the set-up of DRM, in order to select and set-up the tools which protect the licensed material; and the set-up of domains, in order to create user domains, whether they are geographical (home, corporate) or listed (communities). This module should include an interface which facilitates communication between the user and the rest of the system (fundamentally from the access manager) in both directions.

The access manager module (AM) represents the central module of the platform, as it houses the intelligence necessary to control the flow of information within the system. It connects to and receives information from the front-end through the interface and, based on the status of the transaction and interaction with the user, decides which other module of the system should act and with what task. The functions of this module are to monitor the status of the system, determining whether or not the other modules are operational; to receive the instructions given by the user from the web interface provided; to assign the tasks detected in the analysis to the appropriate module within the system; to control the task execution flow and the data flow; to provide confirmation to the user of the execution of the instructions given; to monitor errors and determine the appropriate actions. It is therefore a control module within the system, and does not therefore directly carry out any task in relation to the content or the data.

The activity manager module (ATM) is responsible for search operations in the content database, as well as the monitoring of the activity undertaken in it. Four components are necessary for an efficient design: an index structure, which enables fast searches in the database content; a search engine, which physically carries out the search in the group of indices; a user monitor, which carries out the monitoring of user activity; and a content monitor, which carries out the monitoring of the activity in each content for statistical purposes, calculation of bonuses, etc. This module does not modify the content or add information to the associated data structure.

The catalogue manager module (CM) is responsible for database accesses and concurrences, avoiding collisions. It consists of three components in its design: the database itself, where the content and all the data associated with it is stored in the encapsulated format determined for the platform (MPEG 21 DI, DMP DCI technologies, etc.); the database manager, which is responsible for receiving the requests for access to content and processing them, whether they relate to registrations, cancellations, modifications or the extraction of information; and the content import manager, a special module which anticipates the possible overloading of the system when a content supplier with an extensive catalogue joins the platform. In order to avoid the unnecessary repetition of the registration process for each piece of content, a fast registration mode is provided in which use is made of any information which is repeated when all the content comes from the same provider and, in addition, any possible metadata which this provider has stored in association with its content.

The transaction manager module (TM) is the most important module in the system, as it is responsible for gathering, formatting and adding the information necessary for the management of the content of the E2E DRM platform, setting up all the services offered to its users. It consists of the following components: 
- The identity manager (IM), which is responsible for managing the information relating to a user who requests the service. Its functions include user authentication, user registrations, domain registrations, formatting and the addition of information.

- The licence manager (LM), which is responsible for managing the information relating to licences within the system. Its functions include facilitating the construction of the different use and distribution licences for the user, formatting the information on licences and including it as part of the metadata associated with the content stored in the database, carrying out the verifications of licences when a user requests access to a particular content, and including the information relating to the licence under which the content is provided in the data package sent to the user.

- The payment manager (PM), which is responsible for the financial aspects inherent in any transaction which takes place in the system.

The service manager module (SM) is responsible for managing the service for the user, providing the content in the format and according to the delivery procedure agreed, the licence information if it is not associated with the content (unbundled) and the DRM tools when these are not available on the user terminal. Its design consists of two specific components: the content server, which at the request of the SM sends the content according to the format and delivery procedure determined by the user; and the DRM server, which provides the codes and DRM tools necessary for the decryption of the content on the user terminal.

In order for the platform content to be made available to the users of mobile devices, where the OMA standard is firmly established, this module must provide for the inclusion of a system for translation from the internal format used in the platform (DI/DCI) to OMA. This clearly increases the chances of penetration of the E2E DRM platform in already existing markets and distribution networks (mobile telephony being one of the best established and with the highest volume of use).

Lastly, the user devices (Dev) can be set-up by any element, hardware or software, by means of which a user can receive, reproduce, manipulate, modify or send a representation of digital content. This concept extends the traditional concept of a device, which in the ACC framework is limited almost exclusively to terminals used for receipt, storage and reproduction. As an example, a user can access the platform in order to download a set of photographs by a particular author and a book of poems by another different author; this user can then create songs with their own music, using some of the downloaded poems as lyrics. Finally, in order to distribute their work they can use the set of photos, also downloaded, in order to create a multimedia presentation along with the songs created.

\section{Business models and scenarios}

There are currently four sectors which are of particular importance from the perspective of supporting DRM schemes for the protection of entertainment content: mobile telephony, fixed broadband communications, transmissions (TV) and the electronics industry. To this should also be added the increase in the social network sites and sites with content created by users, which have generated a new and vitally important element for the DRM industry today. The concept which best describes this development, which uses exclusively the capacities inherent in the Internet, is known as the participative web (OECD, 2006), which represents the growing influence of Internet based on new technologies which help the user to become a contributor in the production, development, collaboration and dissemination of Internet content.

The business possibilities, although extensive, require the consideration of a set of scenarios which enable focused analysis to be carried out and identify and maintain competitive advantages for the various agents involved. Within this scope, four business models are considered:

\subsection{Scenario 1: distribution of multimedia content for portable devices}

This model is based on the use of devices for reproducing content which support the adopted standards. The content can be reproduced from local or on-line storage, or may be acquired from the portable device. In addition to the traditional rights of use, we would also have to add digital rights of use, such as the adaptation of content for its use in different situations, verification of content integrity and authenticity, user authentication processes and methods, determination of rights, software verification and authentication, and encryption and decryption. From the licence perspective, the model would enable licences to be linked to specific content, to a user or groups of users, or to a device or group of devices, in addition to their verification and authentication. One of the main benefits would be that music users would be able to easily access an unlimited selection of content irrespective of their location.

\subsection{Scenario 2: distribution of content by means of shared files based on a voluntary collective licence}

This business model is aimed at music users who share digital files on the Internet and are willing to voluntarily pay a certain fee, which allows them to download and share music files using the hardware and software platforms of their choice. An example could be found in the radio stations which pay a fee to authors' societies for the music played. In addition to the traditional rights of use supported we would also have to add the digital rights of use, such as the distribution of content via P2P, the carrying out of electronic transactions and a monitoring system which enables the appropriate distribution of profits. The benefits to be obtained would include the fact that music users can legally access an unlimited selection of musical works and that independent creators can easily distribute their creations.

\subsection{Scenario 3: issue of controlled content}

This business model is based on the issue of content with rights which are digitally signed, enabling them to be received by all users, and which may be compatible with different types of services (public service, commercial service, subscription service). A business example would be the issue of content on analogue television once it has been monitored through decoding devices which enable the receipt and decoding of the digital television signal. In addition to the traditional rights of use supported we would also have to add the digital rights of use, such as on-line storage of a large number of digital files, simultaneous issue for a large number of receivers, making the content accessible for anyone connected to the network, authentication of devices, assembling content in order to create new content, automatic extraction of content characteristics, integrity verification, content authentication, user authentication and automatic generation of a digital trace. From the licence perspective, the model would enable licences to be linked to specific content, to a user or groups of users, and to a device or group of devices, in addition to their verification and authentication. The advantages offered by this business model include the fact that the users would obtain a wide range of benefits as a consequence of the fact that it enables the distribution of content for an unlimited number of receivers in such a way that the rights holders would retain control of the content. 


\subsection{Scenario 4: open distribution structure}

This business model identifies each of the interfaces involved, from the content creator to the end user, in turn allowing third parties to develop compatible software and hardware (Välimäki, 2004). As a business example, reference could be made to the fact that the open distribution structure is characterised by standardising the interfaces and the relationships between the members of the value chain, thereby maintaining the potential for future developments and enabling their adoption by software owners and open code developers.

In addition to the traditional rights of use supported, we would also have to add the possibility of choosing the security of digital rights of use, due to the fact that the development possibilities are in principle unlimited, including the on-line storage of a large number of digital files, simultaneous issue for a large number of receivers, carrying out electronic transactions, content identification and monitoring, verification of the content integrity and quality, verification of the software integrity, personalisation of the interface, and encryption and decryption of the content.

From the licence perspective, the model would enable licences to be linked to specific content, to a user or groups of users, and to a device or group of devices, in addition to their verification and authentication. The benefits to be obtained would also include the flexibility and speed of development, and a closer relationship with the user, enabling their needs to be discovered and the development of a specific product.

\section{Conclusions}

Current studies on DRM have focused on security and encryption as a means of solving the issue of illegal copying by purchasers. If we merely consider content protection and the relationships among the members of the multimedia content value chain who do not trust each other, content should be protected not only among purchasers but also among other members of the chain. DRM as understood by the present work is more than a purely defensive protection of digital content. Rather, it is the foundation for creating a digital ecosystem of rights, rights holders and rights users.

Through this in-depth study, the authors propose an End-to-End Digital Rights Management model which covers content protection throughout the multimedia content value chain and establishes the design of a specific architecture incorporating different technologies (standards) which can be applied based on the interoperability and integrated management of all the intellectual property which is generated throughout the value chain in the content creation process.

The proposed E2E DRM model can adequately reflect real content distribution without any modifications and can easily be expanded for distributors and retailers to reprocess content extracted from DRM-enabled content in a trust-creation environment. The design has incorporated the results of international groups dedicated to interoperability standards such as DMP, MI3P, the Coral Consortium, the Marlin Project, Sun Dream and OMA DRM.

The methodology followed when undertaking this study has been orientated towards a practical business case which encompasses the following realms: interoperability between content sharing businesses and technologies; licensing of contents in different value chains for various intellectual property representations, on the basis of content type and roles; association of licence with the user and its separation from the service; portability of licenses between businesses (transferring of rights to the different systems); support for complex business models; methods of interoperability transactions; methods for representation, identification, authentication and certification of content for users and groups of users; generation and use of content metadata in the intake and operations to produce commercial offerings for various channels or platforms (mobile, Internet, TDT); on-line digital audiovisual content business models based on an increase in non-professional independent content.

Finally, we discuss how this model can be used to successfully support complex business models through the consideration of four scenarios that synthesise a variety of boundaries related to four different sectors (mobile telephony, fixed broadband communications, transmissions and the electronics industry).

\section{References}

Camp, L. J. (2003). First principles of copyright for DRM design. IEEE Internet Computing, 7, 59-65.

Cohen, J. E. (2003). DRM and privacy. Communications of the ACM, 46(4), 46-49.

De Miguel, P. A. (2000). Derecho privado de internet. Madrid: Civitas.

Eisenhardt, K. (1989). Building theories from case study research. Academy of Management Review, 14, 532-550.

ENTER. (2007).IE Business School centre for the analysis of TIS DigiWorld 2007. Los retos del mundo digital Madrid: Idate Foundation.

Eschenfelder, K. R. (2005). The limits of DecSS posting: A comparison of internet posting of DVD circumvention devices in the European Union and China. Journal of Information Science, 31(4), 317-331.

Foroughi,A., Albin, M., \& Gillard,S.(2002). Digital Rights Management:A delicate balance between protection and accessibility. Journal of Information Science, 28(3), 89-95.

Gasser, U, \& Palfrey, J. (2007). Breaking down digital barriers: When and how ICT interoperability drives innovation. Harvard University: Berkman Publication Series.

Gauvin, M., Delgado, J. (2006): Value chain ontologies for intellectual property objects. IPDM'06 (Europe-2006).

Hanaoka, G., Ogawa, K., Murota, I., Ohtake, G., Majima, K., Gohshi, S., Oyamada, K., Namba, S., Imai, H. (2004): Managing encryption and key publication independently in Digital Rights Management Systems, IEICE Transaction on Fundamentals of Electronics, Communications and Computer Sciences Vol. E87-A, 1.

Hare, C. (1999). Towards an ontology of intellectual property: A suggested reconstruction. American Journal of Economics and Sociology, 58(2), 285-297.

Huang, T. (2007). Evolvement of DRM schema: From encryption to interoperability and monitoring. In Multimedia content analysis and mining. Berlin, Heidelberg: Springer., p. 65-75.

IDC. (2007). IDC predictions 2007: Prospering in an era of hyperdistuption. Massachusetts: IDC.

Jeong, Y., Yoon, K., \& Ryou, J. (2005). A trusted key management scheme for Digital Rights Management. ETRI Journal, 27(1), 114-117.

Koenen, R. H., Lacy, J., Mackay, M., \& Mitchell, S. (2004). The long march to interoperable Digital Rights Management. IEEE Proceedings, 92(6), 15-19.

Koepsell, D. R. (2000). The ontology of cyberspace: Philosophy, law, and the future of intellectual property. Chicago and La Salle: Open Court.

Lee, J., Hwang, S., Jeong, S., Yoon, K., Park, C., \& Ryou, J. (2003). A DRM framework for distributing digital contents through the Internet. ETRI Journal, 25, 423-436.

Lichtenthaler, U. (2007). Trading intellectual property in the new economy. International Journal of Intellectual Property Management, 1(3), 241-252.

McAllister, N. (2002). Freedom of expression: Emerging standards in rights management. New Architect, 7(3), 36-39.

Mulligan, D.K., Han, J., Burstein, A.J. (2003). How DRM-based content delivery systems disrupt expectations of personal use. Proceedings of the 2003 ACM Workshop on Digital Rights Management, p. 77-88.

OECD. (2006). OECD information technology outlook 2006. Paris: OECD.

OECD (2007). Participative web: User-created content, directorate for science, technology and industry, working party on the information economy. DSTI/ICCP/IE(2006)7/Final, Paris: OECD.

Pettgrew, A. M. (1990). Longitudinal field research on change: Theory and practice. Organization Science, 1, 267-292.

Sibert, O. (1995), DigiBox: A self-protecting container for information commerce, 1st USENIX Workshop on Electronic Commerce.

Torres, V., Rodriguez, E, Llorente, S., \& Delgado, J. (2005). Use of standards for imple menting a multimedia information protection and management system. In 1 st International Conference on Automated Production of Cross Media Content for MultiChannel Distribution (AXMEDIS 2005).

Torres, V., Delgado, J. Llorente, S. (2006). An implementation of a trusted and secure DRM architecture. On the Move to Meaningful Internet Systems 2006: OTM 2006 Workshops, Lecture Notes in Computer Science (LNCS) 4277, p. 312-321.

Välimäki, M. (2004). A practical approach to the problem of open source and software patents. European Intellectual Property Review, 26(12), 523-527.

Välimäki, M., \& Oksanen, V. (2006). DRM interoperability and intellectual property policy in Europe. European Intellectual Property Review, 26(11), 562-568.

Vălimäki, M., \& Pitkanen, O. (2001). Digital Rights Management on open and semiopen networks. In WIAPP 2001 Proceedings (pp. 154-155).

Van Tassel, J. (2006). Digital Rights Management. Protecting and monetizing content. Elsevier: Focal Press. 
Von Lolmann, F. (2002). Fair use and Digital Rights Management: Preliminary thoughts on the (irreconcilable?) tension between them. Computers, Freedom G' Privacy, April (2), 9.

Wotld Intellectual Property Organization. (1996). World copyright treaty. Geneve: WIPC).

Wotlock, D. R, (2000). After content: The business of intormation in the postcopyright age. Business information Review, 17(12), 191-197.

WSIS. (2007). UNESCO's basic texts on the information society. Paris: UNESCO.

Yin, R. K. (1994). Case study research: Design and methods, London: Sage.

Antonio Hidalgo is professor and director of the Research Group of Innowation, IPR and Teclinology Policy, and director of the Master and Doctorate Programme in MoT, Universidad Politécnica de Madrid, Spain. He received his PhD in industrial engineering from the Universidad Politécnica de Madrid in 1992. He has acted as expert to the European Commission as technology consultant in the European Innovation Monitoring System. His works have appeared in Production. Planning and Control Jounal. Joumal of intelligent Manufactaning, Joumal of Technology Transfer, International journat of Product Development, and International Journal of Enremprenetirship and innovation Management. He teaclies teclmology st rategy to MBA/PhD students and executives.

Jose Albors-Gartigos a full professot of linnowation Management and New Product Development at Universidad Politécnica de Valencia, Valencia, Spain. He holds a PhD Universidad Politécnica de Madrid, Spain. He has published mote than 20 papers in national and international journals.

Vicente Lopez is an industrial engineet and reseatcher in the Research Group of Innovation, IPR and Teclınology Policy at the Universidad Politécnica de Madrid. He has a grant from the Torres Quevedo Programme. He received his PhD in technical sciences from the Polytechnic of Poznan, Poland. He has been working since more than thirty years as a professor and researcher in universit ies in México, Cuba Poland, Puerto Rico and Spain in various subjects such as organizational development, business administration and strategic management. His current research tocuses on industry-science relationships and teclinology transter in Eu ropean and in Latin-American countries. 